\title{
Formation of Marketing Strategy at Environmentally Determined Enterprise
}

\section{Ulyana A. Pozdnyakova}

Ph.D., Volgograd State Technical University, wua@list.ru

Marina E. Buyanova

Doctor of Science, Volgograd State University, buyanovam@rambler.ru

Irina M. Budanova

Ph.D. in Economics, Moscow Institute of state and Corporate Management, im2657002@yandex.ru

Tatyana L. Bezrukova

Doctor of Science, Voronezh State Forestry Engineering Academy, bezrukova_t_l@mail.ru

\author{
Aleksey F. Rogachev \\ Volgograd State Agricultural University, rafr@mail.ru \\ Vyacheslav V. Golikov
}

Ph.D. in Economics, Volgograd State Agricultural University, Volgograd, Russia

Doi:10.5901/mjss.2015.v6n5s1p369

\begin{abstract}
Actuality of this research is caused by necessity for implementation into practice of economic activities of Russian enterprises of modern methods of ecological marketing which should adequately reflect ecological aspects of enterprise's activity of its operative component (preparation and implementation of the process of production and provision of services) and of the sphere of management (including cooperation of enterprise with external environment as to problems of ecology and its obligations, including waste recovery), for the purpose of maximal reduction of possible negative consequences for ecosystem and human. Under modern market conditions, ecological marketing is gaining larger significance in the formation and implementation of functions of ecological policy of enterprise, which is caused by increase of responsibility of producers of goods and services before consumers and society in whole. Ecological marketing gives the possibility not only to implement the process of strategic target setting but also shows solutions to many difficulties related do emergence of ecological risk. At that, perceiving of ecological risk by society largely determines the relation of specific enterprise (or type of technology, products, or services) in no lesser way than actual characteristic of influence of production process. This circumstance, which characterizes the actuality and importance of a problem, determined the topic of this article. The conducted research pursued scientific \& practical goals which correspond to tasks of formation of modern marketing strategies at environmentally determined enterprise.
\end{abstract}

Keywords: ecological marketing, strategy, management, enterprise

\section{Introduction}

Specific environmentally determined features of ecological product, being the key elements of the complex of ecological marketing, participate in almost all flows of entrepreneurial activities (marketing, production, trade, and informational) [Dahlstrom, 2010]. Managing the process of promotion of ecological products and of formation of consumer preferences through implementation of directions and forms of ecological marketing has a strategic character. Possible marketing strategies of environmentally determined enterprises will differ by a range of peculiarities. The process of selection and development of marketing strategy may be interpreted as formation of marketing complex and differentiated into stageby-stage strategies of improvement of ecological indicators, aimed at the increase of company's efficiency and its full 
socio-economic development: strategy "Strategic research (product/market)", strategy "Ecodesign. Evaluation of product's life cycle", strategy "Clean production", strategy "Optimized production", strategy "Communicational system", strategy "Minimization of waste".

\section{Research Methods}

The base of the chosen methodology of research is comprised of principles of integrity and difference, deductive and inductive research methods, statistical processing and generalization of information, and retrospective analysis. Informational basis of the research are the data of expert interview, surveys, and focus groups.

The purpose of this article is formation of complex of measures of ecological marketing for "MarkA" marketing agency, as a structural department of the university, with which it was created and functions now. In order to achieve this aim, the following tasks should be fulfilled: development of marketing strategies which could be implemented by environmentally-oriented companies, determination of the stages of these strategies and of their content.

Instrumentarium and methodological framework of the research, used for solving these tasks, includes a range of general scientific and special methods: structural analysis, abstract and logical analysis, comparative analysis, systemic approach, quantitative methods, and graphical methods of research. Using these methods allowed making substantial, reasoned, and well founded conclusions as a result of conducted research.

Let us view the developed strategies of ecological marketing.

1. "Strategic research (product/market)" is a systemic analysis of efficiency of designing as to external environment, healthcare, and safety during the whole life cycle of product.

Stages of marketing strategy: 1. Market research; 2. Evaluation of influence on the external environment; 3. Product development; 4. Holding seminar for introduction and discussion of ideas; 5 . Development of strategies of projecting; 6 . Selection of ecologically safe materials; 7. Refusing toxic and hazardous materials; 8 . Achievement of maximal efficiency of energy use while producing and using; 9 . Achievement of maximal efficiency of using waster during exploitation; 10. Engineering, oriented at minimization of losses.

Main content of the strategy "Strategic research (product/market)":

1) Introduction - determining the project's goal; enumeration of specific goals;

2) General requirements - determining the main function of product; formulating requirements to the service life; enumeration of aesthetic ideas; determining ergonomic requirements; enumeration of requirements and safety problems; determining requirements to efficiency and quality.

3) Tasks of ecological security - enumeration of specific strategies, belonging to materials, efficiency, and waste utilization after the end of service life, etc.

4) Requirements to production - determining production requirements and limitations; inclusion of any tasks and goals.

5) Rules/norms and standards - enumeration of all obligatory rules, standards, and accesses, which have relation to product;

6) Expenses - allocation of limitations for product cost, in order to guarantee its competitiveness.

2. Strategy "Ecodesign". Evaluation of the "products' life cycle", is primarily a method of evaluation of influence on ecology, caused by certain product/service. This activity is divided into four stages: determining the goal and sphere of activity; analysis of the life cycle of material \& technical reserves; evaluating the influence of the life cycle on the external environment (depletion of ozone layer, greenhouse effect, gas emissions and acid rains, etc.); interpretation of life cycle. Secondly, the strategy supposes the determination of possible directions of ecological certification for the purpose of further creation of product's ecodesign [Harkova, 2014].

3. Strategy "Clean production" - optimized production, aimed at the increase of productiveness and ecological efficiency, which possesses one or more of the following attributes:

- Using fewer raw materials;

- Using recycled materials;

- Reducing the quantity of material types for simplifying the waste utilization;

- Reducing the usage of package materials;

- Using the renewable energy sources;

- Refusal from chlorine-containing plastic and solvents,

- Reducing the usage of energy and natural resources (earth, water, bioresources, etc.);

- Reducing the volume of waste; 
- Using components which may be used repeatedly;

- Reducing the level of noise and odor distribution.

4. Strategy "Optimized production" is a systemic elimination of problems, in the most general form (with overproduction, waiting, transportation, excessive reserves, moving, excessive processing operations, defects) and implementation of concepts of continuous technological process and sale. Optimized production is basically a systemic reduction of non-production costs (overproduction, down time, transportation, stock reserves, moving, excessive operation during production, defects) and practical implementation of concepts of continuous technological flow and account of consumer demand.

Optimization of production is determined by five factors: costs, quality, supplies of final product, safety, and personal attitude of employees. Implementation and mastering of the system of optimized production gives the following advantages: reduction of losses by $80 \%$; reduction of product cost by $50 \%$; reduction of length of production cycle by $50 \%$; reduction of labor costs by $50 \%$ with preservation or increase of efficiency; reduction of stock reserves of components by $80 \%$ with increase of the level of client service; increase of efficiency by $50 \%$ with the same production capacity; increase of quality; increase of profitability; improvement of flexibility of the system as to reaction to changes, related to increase of requirements to the quality; concentration on strategic approaches; increase of financial flow by means of increase of frequency of shipping and invoices. The key components are elimination of losses, continuity and comprehensiveness of technical process, and consumer demand. When these elements are applied to the spheres of "costs", "quality", and "supply", this creates the basis for optimized production.

5. Strategy "Communicational system" is, primarily, the study of market and provision of all elements of marketing process with necessary and timely information about the company and its rivals influencing the external environment. Information about ecological efficiency of the company's activities in whole is a basis for making marketing decisions [Volosatova, 2014]. That's why entrepreneurial companies that use strategies of ecological marketing should create a system of marketing ecological information. This will allow them from accidental activities to the planned gathering and processing of information. These informational systems will allow the managers to make effective decisions and function as a database for responses to queries from the company's market partners. Secondly, it is provision of information to consumers and market partners about ecological aspects of products and processes. That's why the product management should be prevailed by approach which consists in the fact that all who contact the product after it leaves the plant should receive councils and recommendations as to exploitation and utilization of the product.

6. Strategy "Minimization of waste" is a sequence of cyclic systems, in which materials are used repeatedly or recycled within a closed process. Within this strategy, an enterprise can choose one or several following strategies.

1. Reduction of reasons for waste appearance:

- Simplification of products, exclusion of useless components;

- Minimization of the use of materials, necessary for provision of working characteristic of product;

- Elimination of excessive packaging;

- Using strong and light materials;

- Increase of service life of product;

- Allocation and elimination of potentially weak elements and construction - especially among working components;

- Predetermination of protection against wrong use;

- Provision of convenient service and repair for a customer;

- Consideration of possibility of use of classical design and other means which may urge a consumer to use a product over longer period.

2. Utilization of products and materials:

- Simple products (packaging and other products of the same material).

- Use of materials which can be recycled by popular means;

- Providing the materials of stickers, glues, and caps to be compatible with the main material of a product (or to be removed in the process of recycling).

3. Dismantling and recycling:

- Minimization of materials assortment;

- Use of compatible materials;

- Reduction of the number of assembly operations;

- Simplification and standardization of fitting and connection of components; 
- Identification of dividing point of components;

- Marking the materials for their division during utilization.

4. Minimization of materials use:

- Designing a product with minimal use of additional materials;

- Warning consumer when replacement of consumable materials requires preservation of waste.

Selection of marketing strategy, determination of its structure and conditions for cooperation and implementation of its internal elements is a strategic decision which determines the long-term efficiency of entrepreneurial activities on the whole. Let us describe the peculiarities of formation of the complex of marketing measures as to promotion of products by environmentally determined enterprise to the market. Implementation of these measures is a stage-by-stage process of realization of small marketing strategies.

\section{Analysis Result}

Thus, the process of implementation of the above mentioned marketing strategies is promoting environmentally determined enterprises is a complex of marketing measures which suppose the formation of the chain of marketing actions, the development of which takes into account the existing ecological problems. The enterprises, the strategies of which are developed with account of the principles of ecological marketing, show that they "do care" - firstly, they harnessed the eco-trend; secondly, can gain profit from this trend; thirdly, the brand receives support from the growing number of societies which are focused on the ecological conception of consumption.

The offered marketing strategies can be adapted to any specifics of enterprise, type of property, target market, and manufactured product, which was performed by us as to the structural department of MarkA marketing agency which is working with the department of International economics and economic theory of Volgograd State Technical University. Despite the specificity of the company, there was developed a complex of measures for ecological marketing, which allowed acquiring new possibilities and advantages. The complex of marketing measures has the following schematic form (Fig. 1).

\section{Strategic Research}

\subsection{Holding a seminar for the purpose of introduction and discussion of ideas.}

Gathering environmentally determined employees, considering the possible ways of taking the path of ecological business, and studying the existing projects which will allow implementing the concept of ecological business.

\subsection{Developing the strategy of design.}

Selecting the project which will allow implementing the concept of ecological business: "Green' office" projects, which is created and implemented with support from the Greenpeace Russia.

4.3 Systemic analysis of efficiency of design as to external environment, healthcare, and safety during the whole life cycle of a product.

Studying the experience of other companies as to participation in a similar project and making conclusions about possible efficiency. 


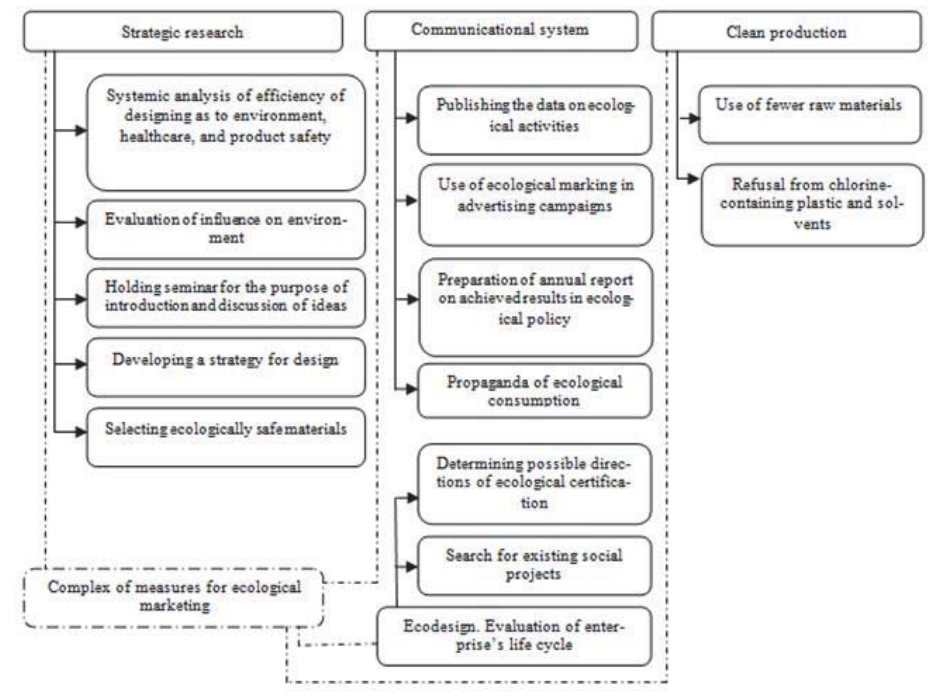

Figure 1. Complex of measures for ecological marketing for MarkA marketing agency

Source: compiled by the author

\subsection{Evaluation of influence on the environment}

The influence on the environment may be evaluated with the help of certain indicators. For example, by replacing electromagnetic actuators in tubular luminescent energy-saving lamps to electronic ones, it is possible to reduce the electricity expenses by $30 \%$. Saving electricity helps to reduce toxic emissions at thermal electric power stations and greenhouse gas emissions, which is very important for fighting the global climate change. It is possible to save heat by installing heat regulators on heaters and by reducing heat supply outside working hours (with such regulation, heat consumption is reduced by 2 times). A significant spending pattern for many consumers is payments for water usage and water disposal (as experience shows, the measures for water saving with installation of water meters allow reducing the costs by $20-40 \%)$.

A significant part in recommendation of "Green' office" belongs to resource saving. The primary item is office paper. Replacement of 1 ton of paper of primary cellulose to paper of waste paper will help to save 20-25 trees from being cut. As the recycled waste paper is hard to find, it is recommended to choose the paper which is certified according to the scheme of FSC (Forest Stewardship Council). This confirms that the paper material was obtained as a result of ecologically and socially responsible forest use.

\subsection{Choosing ecologically safe materials}

This measure consists in considering the possible measures as to the used office. It is impossible to use energy saving lamps in the office of MarkA marketing agency, as the design of the building supposed the use of installed luminescent lamps. Due to administrative rules, in is impossible to change that in the near future. However, it is quite possible to switch to usage of office supplies and interior items without PVC.

\section{Ecodesign. Evaluation of Enterprise's Life Cycle}

\subsection{Search for existing social projects.}

Considering possible social and ecological projects and choosing the project which can be implemented at the current stage of enterprise's life cycle. 


\subsection{Determining possible directions of ecological certification.}

Search for possible directions of voluntary ecological certification.

\section{Clean Production}

\subsection{Use of fewer raw materials}

This measure can consist in the use of double-sided printing, which will allow reducing the consumed natural resources and saving administrative expenses.

\subsection{Refusal from chlorine-containing plastic and solvents.}

This measure supposes the refusal from disposable cutlery, plastic windows, and office supplies and interior items of PVC.

\section{Communicational System}

\subsection{Publishing the data on ecological activities.}

The information can be published on the web-site and other resources. For example, MarkA marketing agency approved the publication of the data on its ecological policy at the Greenpeace Russia web-site.

\subsection{Use of ecological marking for advertising campaigns.}

As a result of entering the project, the agency received official permission to use the logo of the project, including promotional campaigns.

\subsection{Preparing annual report on achieved results in ecological policy.}

MarkA marketing agency plans to publish the annual report on the achieved results in ecological policy on its web-site and the Greenpeace Russia web-site.

\subsection{Propaganda of ecological consumption.}

All employees should take part in the process of resources saving. Various forms of propaganda can be used for that. It is possible to place motivation posters in the office, hold educational lectures and ecological parties, hold competitions for determining the most ecologically responsible employee, etc.

The above viewed complex of marketing measures is created on the basis of the developed theoretical recommendations for designing marketing strategies of environmentally determined enterprises. The offered private strategies can be used as a basis by any company, to be turned into a comprehensive complex of measures. A complex of measures may also be developed on the basis of several types of strategies (as was done for MarkA marketing agency), as well as on the basis of one strategy.

\section{Acknowledgments}

The research was made with financial support from the Russian Humanitarian Science Foundation. Project No. 15-2201011 "Theoretical and methodological foundations for marketing provision of innovational development of intellectual resources of the Republic of Belarus and the Russian Federation under the conditions of economic integration (by the example of universities of business type)"

\section{References}

Dahlstrom, Robert, 2010. Green Marketing Management. Cengage Learning, pp: 360. 
Harkova, N.N., U.A. Volosatova, M.V. Rossinskaya and A.S. Sidorenko, 2014. Peculiarities of Environmental Certification on the Russian Market // World Applied Sciences Journal. Vol. 30. No. 3. pp. 381-383.

Volosatova, W.A., P.V. Shvagerus, E.G. Popkova and I.M. Budanov, 2014. Conceptual Approach to Ecological Information Marketing System Formation at the Russian Market // World Applied Sciences Journal. Vol. 30. No. 8. pp. 1020-1023. 